\title{
Golpe no Brasil: o que a mídia tem a ver com isso?
}

\author{
Flávia Quirino \& Liziane Guazina \\ Universidade de Brasília \\ E-mail: flaviaquirino@gmail.com/liziane.g@uol.com.br
}

\begin{abstract}
Resumo
Em 2015, o Brasil assinalou um importante momento em sua história: o impeachment que destituiu do poder executivo do país Dilma Rousseff. O processo de ruptura democrática, levado a cabo no dia 31 de agosto de 2016, com a votação no Senado Federal, veio acompanhado de um apanhado de manifestações, envoltas na euforia das denúncias de corrupção, e, também na crise econômica, termo cativado e angariado por muitos setores, sobretudo os empresariais, para justificar o afastamento da Presi-

denta. Este artigo, que é parte de uma pesquisa ainda em andamento no Programa de Pós-Graduação da Faculdade de Comunicação da Universidade de Brasília, tem como proposta levantar questões e reflexões, com base na teoria do enquadramento, sobre o papel da mídia no processo de impeachment de Dilma Rousseff, a partir de uma análise de notícias veiculadas no jornal Folha de São Paulo, em eventos que ocorreram nos meses de março e dezembro de 2015 .
\end{abstract}

\section{Abstract}

In 2015, Brazil marked an important moment in its history: the impeachment that deprived of the executive power of the country Dilma Rousseff. The process of democratic rupture, carried out on August 31, 2016, with the vote in the Federal Senate, was accompanied by a gathering of demonstrations, surrounded by the euphoria and of corruption reports, and also in the economic crisis, a captivated term by many sectors, especially business to justify the re- moval of the President. This article, which is part of a research still underway in the Graduate Program of the Faculty of Communication of the University of Brasília, aims to raise questions and reflections, based on framing theory, on the role of the media in the process of impeachment of Dilma Rousseff, based on an analysis of news published in the newspaper Folha de São Paulo, in events that occurred in the months of March and December of 2015.

\section{Introdução}

D ECEnTEMEnTE, o Brasil assinalou mais um importante momento em sua história: o processo de impeachment que destituiu do Poder Executivo do país a primeira mulher eleita presidente da República, Dilma Rousseff, levado a cabo no dia 31 de agosto de 2016 com a votação no Senado Federal.

Data de submissão: 31/05/2017. Data de aprovação: 30/06/2017.

A Revista Estudos em Comunicação é financiada por Fundos FEDER através do Programa Operacional Factores de Competitividade - COMPETE e por Fundos Nacionais através da FCT - Fundação para a Ciência e a Tecnologia no âmbito do projeto Comunicação, Filosofia e Humanidades (LabCom.IFP) UID/CCI/00661/2013.
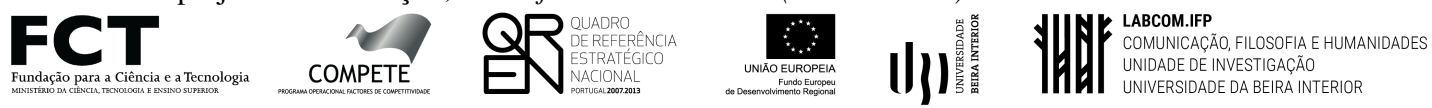
O impeachment de Dilma Rousseff foi acompanhado de um apanhado de manifestações, envoltas na euforia das denúncias de corrupção, e, também na crise econômica - termo-chave utilizado por muitos setores, como o empresarial e legislativo para justificar o afastamento da Presidenta. A crise econômica vivida e sentida em vários países e regiões do globo se transformou no país também em crise social, ambiental e política.

Este artigo, que é parte de uma pesquisa ainda em andamento no Programa de Pós-Graduação da Faculdade de Comunicação da Universidade de Brasília, tem como proposta levantar questões e reflexões sobre o papel da mídia no processo de impeachment de Dilma Rousseff, a partir de uma análise de notícias veiculadas no jornal Folha de São Paulo, em eventos que ocorreram nos meses de março e dezembro de 2015.

O artigo está estruturado da seguinte forma: apresentamos um referencial teórico, a abordagem metodológica, seguida por uma análise das notícias, a partir das funções de enquadramento. Nas considerações finais, discutimos os resultados da análise que tem como contexto de fundo de uma compreensão do papel da comunicação para a democracia brasileira.

\section{Contexto político na América Latina e, consequentemente, no Brasil}

Ao observar a situação política brasileira, é importante demarcar que esta realidade não está dissociada dos contextos político, econômico e social de toda a América Latina, principalmente a partir da vitória de Hugo Chávez na Venezuela (1998), que inaugurou diversos governos de esquerda, ou ditos progressistas, nos anos 2000. De acordo com Harnecker (2010), neste período, pela primeira vez na história da América Latina grupos de esquerda e centro-esquerda conseguiram que seus candidatos triunfassem na maior parte dos países da região levantando bandeiras antineoliberais.

Em 2000 vence Ricardo Lagos no Chile; em 2002 Lula no Brasil; em 2003 Néstor Kichner na Argentina; em 2005 Tabaré Vázquez no Uruguai e Evo Morales na Bolívia; em 2006 Michelle Bachelet no Chile, Rafael Correa no Equador e Daniel Ortega na Nicaraguá; em 2008 Fernando Lugo no Praguai; em 2009 Maurício Funes em El Salvador e Rafael Correa é reeleito no Equador, Mujica vence no segundo turno no Uruguai e Evo Morales é reeleito na Bolívia com ampla maioria (Harnecker, 2010, p. 7).

Após as duas vitórias de Lula nas eleições de 2002 e 2006, o Partido dos Trabalhadores (PT) encabeçou e saiu vitorioso nas duas eleições seguintes, elegendo Dilma Rousseff como Presidenta da República, cargo que ocupou até o seu afastamento definitivo em agosto de 2016.

Assim como no caso brasileiro, países como Honduras e Paraguai também acentuaram em suas histórias o afastamento de presidentes democraticamente eleitos nos anos de 2009 e 2012, respectivamente. Além de possuírem semelhanças significativas em sua essência, estes processos apontam para um maior aprofundamento e compreensão do papel da mídia nestes momentos decisivos da vida política de um país.

Para Alvarez e Novion (2016) "mais importante do que avaliar as semelhanças com os golpes do passado", o caso de Honduras, por exemplo, é uma oportunidade para entender o atual ciclo conservador na América Latina, onde a mídia tem uma atuação política privilegiada.

Nessa nova metodologia de golpe, a mídia tem papel fundamental. Agindo coligada a um judiciário e a um Congresso conservadores, confere ao golpe "suave" ares democráticos. Utiliza-se, para isso, uma narrativa liderada por atores supostamente isentos, respaldados por manifestações supostamente espontâneas e "livres de ideologia". (Alvarez; Novion, 2016, p.328)

Em 2014, Dilma venceu a eleição, no primeiro turno com 41,6\% e no segundo foi reeleita com 51,6\% dos votos válidos. A reeleição, no entanto, não foi suficiente para que Dilma Rousseff continuasse o man- 
dato, a crise econômica global, refletida no país, aliada às inúmeras denúncias de corrupção no governo causou insatisfação por parte da população. Sem a maioria no Congresso, Rousseff foi alvo de um processo de impeachment por crime de responsabilidade fiscal, as chamadas pedaladas fiscais. O processo iniciou em dezembro de 2015 com a aceitação do pedido de impeachment na Câmara dos Deputados, depois em abril do ano seguinte a Câmara dos Deputados votou pela admissibilidade do processo e seguiu para o Senado Federal. Em maio, a Presidenta foi afastada pelo Senado para prosseguimento do processo e o vice-presidente Michel Temer (PMDB/SP) assumiu o cargo interinamente até o julgamento final.

A última fase do julgamento aconteceu com a votação dos senadores pelo impeachment em 31 de agosto. O processo de votação, conduzido pelo Supremo Tribunal Federal, foi dividido em dois momentos, o primeiro para a perda do mandato e o segundo sobre a cassação dos seus direitos políticos. Rousseff foi absolvida na segunda votação. "Na tarde desta quarta-feira 31, 61 dos 81 senadores decidiram pelo impedimento de Dilma Rousseff, mas apenas 42 deles foram favoráveis à aplicação da pena de perda dos direitos políticos e da inabilitação de Dilma para assumir cargos públicos", trecho de matéria da revista Carta Capital ${ }^{1}$.

Dois dias depois do impeachment, o Senado aprovou um projeto de lei que permite as pedaladas fiscais, o crime de responsabilidade fiscal da qual Dilma foi julgada ${ }^{2}$.

\section{Notas metodológicas}

O ambiente social é também configurado, em grande parte, pela mídia. Para Porto (2004) a mídia é, frequentemente, entendida como "fonte de informação" e seu papel é definido como o de informar os cidadãos. "Para bem servir a democracia, segundo este enfoque tradicional, a mídia deve transmitir informações de forma objetiva e imparcial para a audiência". Neste sentido, a mídia deveria, ao tratar de assuntos políticos, "impedir que valores e ideologias interfiram no relato dos fatos ou evitar que os meios de comunicação favoreçam um grupo, um partido ou candidato" (p.2).

Buscando conceituar o que é "enquadramento", Porto (2004) identifica alguns teóricos que discorrem sobre o conceito de enquadramento, teoria que tem sido comumente utilizada em pesquisas de comunicação que investigam o papel das notícias na vida política e social das sociedades. Neste artigo, acompanhamos o conceito de enquadramento apresentado por Entman, que o define da seguinte forma,

O enquadramento envolve essencialmente seleção e saliência. Enquadrar significa selecionar alguns aspectos de uma realidade percebida e fazê-los mais salientes em um texto comunicativo, de forma a promover uma definição particular do problema, uma interpretação causal, uma avaliação moral e/ou uma recomendação de tratamento para o item descrito. (Entman, 1994, p.294 apud Porto, 2004, p.8).

O enquadramento tem papel importante no exercício do poder político, "até porque num texto jornalístico, uma framing é uma 'marca de poder', pois registra a identidade dos autores e, particularmente, os interesses que competem para dominar o texto" (Guazina; Prior; Araújo, 2017). Em resumo, os enquadramentos influenciam o modo como os acontecimentos da política são apresentados.

Além da abordagem teórica-metodológica apresentada, fazemos uma composição entre enquadramento e narrativas jornalísticas, tendo o conflito como uma categoria estratégica da cobertura no jornalismo político. Para Guazina e Motta (2010) o conflito está presente na cobertura sobre política porque a própria

1. Em matéria veiculada na internet no dia 31 de agosto de 2016 "Senado Federal aprova impeachment de Dilma", disponível em: www.cartacapital.com.br/politica/impeachment-dilma-faz-sua-defesa-no-senado

2. Ver matéria "Dois dias após impeachment, Senado aprova lei que permite pedaladas fiscais" publicada na editoria de economia do site IG: http://economia.ig.com.br/2016-09-02/lei-orcamento.html 
política é uma atividade centrada em disputas, como jogos. "O relato dos conflitos torna o jornalismo político mais aquecido, mais atraente para a audiência. O conflito atrai a atenção, é facilmente compreendido, tanto pelo jornalista quanto pela audiência". A cobertura do jornalismo política então amplifica e demarca as disputas políticas já existentes.

O conflito (de interesses, de posições) enquanto um frame cognitivo estrutura o enredo da narrativa jornalística, torna os aconteceres isolados em histórias compreensíveis. Colocando continuamente atores uns contra os outros, o narrador-jornal tece as intrigas, promove o conflito que necessita estimular para manter a narrativa jornalística sempre "aquecida" e atraente para o destinatário (Guazina; Motta, 2010, p.137).

A partir do exposto, constitui o corpus de análise deste artigo, matérias veiculadas no jornal, de circulação nacional, Folha de São Paulo ${ }^{3}$ em eventos que antecederam e, portanto, culminaram na concretização do impeachment da presidenta Dilma Rousseff.

Em razão dos numerosos eventos deste processo e da imensa quantidade de notícias veiculadas, optamos por um recorte metodológico que se limita a analisar as notícias publicadas em três eventos préprocesso do impeachment, que são: protestos do dia 13 de março de 2015; protestos do dia 15 de março de 2015 e pedido de impeachment aceito na Câmara dos Deputados em 2 de dezembro de 2015. Escolhemos estes eventos por compreender que dentro do jogo político que se deu o processo de julgamento, eles delimitam o contexto e artimanhas que dão o pontapé inicial no processo de impeachment.

Os "Protestos de Março", que ocorreram logo depois das eleições de outubro de 2014, marca o início de mobilizações e euforia em torno do impeachment. Outras manifestações ocorreriam ainda em abril e agosto de 2015, de ambos os lados: contra e pró-impeachment. Depois disso, em dezembro, a aceitação da denúncia por crime de responsabilidade marca outro momento crucial, que é justamente o início do processo de impeachment. No total, contabilizamos a publicação de 50 notícias relacionadas a estes eventos, localizadas no Primeiro Caderno do jornal e que se concentram na editoria de Poder, conforme Tabela 1 a seguir:

Tabela 1. Quantidade de notícias analisadas por evento

\begin{tabular}{lllc}
\hline & Evento/Cobertura & Data & $\begin{array}{c}\text { Quant. de notícias } \\
\text { publicadas }\end{array}$ \\
\hline & Protestos Contra Impeachment & $12 / 03 / 2015$ & 7 \\
& & $13 / 03 / 2015$ & 4 \\
Pré-processo de & $14 / 03 / 2015$ & 7 \\
\cline { 2 - 4 } impeachment & Protestos Pró-impeachment & $15 / 03 / 2015$ & 6 \\
& & $16 / 03 / 2015$ & 10 \\
\cline { 2 - 4 } & Aceitação do pedido de impeachment & $1 \% / 12 / 2015$ & 8 \\
& na Câmara dos Deputados & $2 / 12 / 2015$ & 4 \\
\hline Total de notícias publicadas sobre os eventos & $3 / 12 / 2015$ & 4 \\
Total de notícias analisadas & & 50 \\
\hline
\end{tabular}

Fonte: Elaboração das autoras.

Inicialmente fizemos um levantamento das notícias veiculadas no jornal para cada evento apresentado em três períodos: dia anterior, dia do evento e posterior, com o objetivo de mensurar a quantidade de notícias publicadas por cada uma das temáticas propostas e avaliar qual dia obteve mais incidência de publicações

3. Maior jornal de circulação impressa e digital do Brasil (2015), segundo dados da Associação Nacional de Jornais. Disponível em: www.anj.org.br/maiores-jornais-do-brasil/ 
sobre o tema. Com essa informação, a análise se deu então, a partir das notícias publicadas no dia posterior a cada evento, como forma de verificar os enquadramentos, a partir da cobertura do veículo sobre os temas apontados.

Com base no recorte analítico da pesquisa, observamos as funções de enquadramento apresentadas por Entman. Para os autores Guazina, Prior e Araújo (2017), as categorias definidas por Entman - as chamadas "funções de enquadramento" - "fornecem subsídios valiosos" para a compreensão dos enquadramentos apresentados pelos veículos de comunicação.

Segundo Entman (Fontenelle, 2017), os enquadramentos noticiosos podem se referir a três classes de objetos: eventos, questões e atores políticos. Os "atores" podem ser indivíduos ou instituições.

Nos enquadramentos, Entman identifica quatro funções, necessárias para que o frame cumpra seu propósito persuasivo: a definição do problema; a identificação de suas causas; a elaboração de uma avaliação; e o endosso de soluções. Nem todas essas quatro funções precisam estar presentes para que se configure um enquadramento típico. Das funções do enquadramento, Entman define como as mais importantes a definição do problema - pois é ela que, em geral, determina o restante do enquadramento - e a solução, pois em geral o objetivo do enquadramento é promover determinado remédio. Diferentes definições levam a diferentes propostas de solução. (Fontenelle, 2017, p.119).

Com base nos estudos de Fontenelle (2017), a partir dos conceitos elaborados por Entman, procuramos identificar estes objetos e funções de enquadramento nas notícias apontadas acima: atores, eventos e questões mais frequentes abordados; os problemas definidos, as causas identificadas, as soluções endossadas e os julgamentos morais. As notícias analisadas foram publicadas na versão digital do jornal Folha de São Paulo, disponíveis na internet ${ }^{4}$.

\section{Análise das notícias}

\subsection{Ato em defesa da democracia - 13 de março de 2015}

Entre os dias 12 a 14 de março de 2015, foram publicadas 18 notícias. Como o foco de análise é a data posterior aos protestos do dia 13, analisamos sete notícias publicadas no dia 14 de março de 2015 .

Nas notícias aparecem como atores principais as centrais sindicais e movimentos sociais. Das sete matérias publicadas com a retranca sobre os Protestos de Março, quatro fazem cobertura dos atos do dia 13 de março. Destas, três matérias destacam que as manifestações foram organizadas por centrais sindicais e movimentos sociais, conforme trecho da matéria "Atos rejeitam impeachment, mas criticam governo Dilma" a seguir: "centrais sindicais e movimentos sociais que organizaram manifestações rejeitaram qualquer possibilidade de impeachment da presidente Dilma Rousseff, mas expressaram insatisfação com os rumos de seu governo e fizeram críticas à sua política econômica".

O evento é o próprio ato do dia 13 de março e as questões mais abordadas é a defesa do governo, com ressalvas. Os problemas identificados nas notícias analisadas no período se dão a partir dos seguintes pontos: a) manifestações foram organizadas por centrais sindicais e movimentos sociais; b) rejeição ao impeachment; c) falta diálogo do governo com a sociedade. A rejeição ao impeachment pelos manifestantes é outro ponto abordado, categoricamente, na matéria "Grupos chamam opositores de golpistas", o jornal diz: "Apesar do tom de cobrança, que incluiu o pedido de revisão de medidas que afetam benefícios trabalhistas, os manifestantes saíram em defesa da Petrobras e do mandato da presidente Dilma Rousseff (PT) e chamaram de 'golpistas' os que defendem o impeachment da petista". Aqui o veículo faz questão de reforçar a qual partido pertence a Presidenta. Na mesma matéria, a Folha destaca que manifestantes

4. Disponíveis em http://acervo.folha.uol.com.br/ 
receberam pagamentos para participarem de ato. "Em São Paulo, manifestantes relataram à Folha terem recebido 'café, almoço e jantar' para estar no ato". Nas notícias, o jornal também enfatiza o protagonismo de organizações como a CUT - Central Única dos Trabalhadores e MST - Movimento dos Trabalhadores Rurais Sem Terra nos atos. Na mesma página em que a matéria destaque "Líder do MST diz que ministro da Fazenda é 'infiltrado' no governo”, o veículo publica mais três notícias sobre os atos pró-impeachment que acontecem no dia seguinte, entre estas: Aécio chama população para marcha anti-Dilma e Bolsonaro protocola na Câmara pedido de impeachment.

\subsection{Ato pró-impeachment - 15 de março de 2015}

A data de 15 de março foi escolhida para uma das primeiras manifestações contrárias ao governo Dilma, após a reeleição em outubro de 2014. Neste dia, o jornal Folha de São Paulo publicou seis matérias que tratam sobre a manifestação. Um dia após a manifestação, em 16/03, o jornal publicou 10 matérias de cobertura do ato pró-impeachment, são nove páginas de conteúdo, com fotos, entrevistas e perfis de pessoas que participaram das mobilizações, a matéria "Caras da avenida", acompanha um box "O que eles querem? Alguns grupos que foram à Paulista", que destaca o perfil de alguns agrupamentos: Fica, Dilma (criticaram a corrupção, mas não defendem impeachment); Pró-impeachment (apoiam a saída de Dilma); Pelos militares (defendem intervenção militar); Vim de graça (diziam que estavam no protesto porque queriam e não por serem pagas, em referência às pessoas que participaram dos atos no dia 13); Turma do barulho (adeptos de apitos, vuvuzelas, etc); Também posso (faziam questão de se assumir como 'elite branca' ou 'coxinha' e defendiam o direito de se manifestarem). Existe uma ênfase em algumas matérias de que as pessoas que foram às ruas no dia 15 eram de todas as classes sociais, como diz o subtítulo de uma análise sobre o ato: "Dimensão dos protestos, que reuniram não apenas gente mais rica e grupos de direita, surpreendeu governo".

O principal problema identificado nesta análise é a insatisfação com Dilma e o PT. A causa desse problema resultou em uma multidão que foi às ruas de todo o país manifestar contra o governo, maior ato desde as Diretas Já. "Multidão vai às urnas contra Dilma e assusta governo" é o título da primeira manchete, que diz em um dos trechos: "Os manifestantes fizeram uma vigorosa demonstração de sua insatisfação com Dilma e o PT, partido que governa o país desde 2003”. Nas contagens da Folha de São Paulo "houve protestos em 153 cidades, incluindo as capitais de todos os estados e Brasília". Na matéria "Tietados, policiais posam para selfies com manifestantes", o jornal oferece outra imagem dos policiais militares que atuam em manifestações: "...acostumados a serem hostilizados em protestos, foram tietados por manifestantes na Avenida Paulista durante o ato contra a presidente Dilma Rousseff neste domingo (15)".

Em outra matéria "Governo tenta reagir repetindo promessas", o veículo diz que a Presidenta ficou indignada com os protestos. No entanto as afirmações da matéria são de interlocutores e não possuem fontes diretas. Nas notícias também ficou evidente à comparação da quantidade de pessoas que aderiram a cada uma das manifestações, contrárias ou em defesa do governo. As notícias apontam como atores dos protestos anti-dilma, os grupos MBL - Movimento Brasil Livre, Revoltados ONLine e Vem Pra Rua, além de cidadãos comuns, conforme aponta uma das matérias: "Movimentos já planejam outros protestos contra Dilma em abril".

Em outra matéria, o jornal avalia que "redutos petistas, como a Bahia e Rio Grande do Norte, também tiveram manifestações com milhares de pessoas". Uma avaliação ao fato do Nordeste ser a região que mais angariou votos para Dilma nas eleições de 2014. 


\subsection{Aceitação da denúncia de impeachment na Câmara dos Deputados - 2 de dezembro de 2015}

Entre os meses de março a dezembro a crise política e econômica no país se intensificou; é o que identificamos nas capas da Folha de São Paulo observando-as, empiricamente. O então presidente da Câmara dos Deputados, Eduardo Cunha (PMDB-RJ) tornou-se um dos personagens principais no processo de aceitação do pedido de impeachment da presidenta Dilma Rousseff. No dia $1^{\circ}$ de dezembro, o jornal publicou uma notícia com o título "Cunha ameaça impeachment e petistas discutem salvá-lo". A matéria aponta as prévias da votação do processo de cassação de Eduardo Cunha, que será votado no Conselho de Ética no dia 2 de dezembro. Na mesma data da votação de seu processo, Cunha resolve aceitar o pedido de impeachment contra a presidenta Dilma Rousseff.

Na edição seguinte (03/12), a Folha de São Paulo destaca a aceitação do pedido de impeachment por Eduardo Cunha como forma de revidar os votos dos parlamentares do PT na Comissão de Ética. Entre as matérias, o jornal apresenta uma linha do tempo para justificar "Como chegamos até aqui" e aponta duas causas principais para a aceitação do pedido de impeachment: altas taxas de desemprego e crise econômica. Identificamos como atores políticos nestas notícias: Eduardo Cunha, Dilma Rousseff, PT. O principal problema apontado na cobertura sobre o dia 2 de dezembro está o fato do PT não ter salvo Cunha na Comissão de Ética, como destaca trecho da matéria: "Em retaliação ao PT e ao Planalto, que não asseguraram votos para enterrar seu processo de cassação, o presidente da Câmara dos Deputados, Eduardo Cunha (PMDB-RJ), anunciou às $18 \mathrm{~h} 38$, desta terça-feira (2) a deflagração do principal pedido de impeachment contra Dilma Rousseff".

Em outra matéria, o jornal diz que Dilma está indignada com a atitude de Cunha. Adjetivar a suposta postura da Presidenta diante do fato é uma forma de avaliação e julgamento moral, a matéria traz no título "Presidente se diz indignada e ataca Cunha", novamente a afirmação sobre a fala de Dilma é terceirizada, conforme aconteceu em notícia analisada no período anterior.

Na linha do tempo que traz acontecimentos marcantes de março a novembro de 2015, estão omissas as informações que tratam das manifestações em defesa do mandato de Dilma Rousseff. Um gráfico sobre a popularidade da Presidenta também é apresentado, para mostrar a evolução da avaliação do Governo no ano de 2015, em 25 de novembro 67\% dos entrevistados do Datafolha reprovavam o governo Dilma.

Nas notícias analisadas nos três períodos, observa-se também que o conflito é colocado como uma categoria estruturante da narrativa jornalística. Segundo Guazina e Motta (2010), é comum o uso dos seguintes verbos nos títulos das notícias: ameaçar, pressionar, rachar, salvar, retaliar, revidar e atacar. Alguns trechos de matérias, sobre o evento do dia 2, dizem: "Dilma partiu para o ataque contra Cunha" ou "a presidente reagiu logo depois". Os personagens promovem o embate necessário à construção de uma tensão. "A tensão permanente aquecida é a essência da construção da narrativa política. É ela que instiga a trama e mantém acesa a curiosidade pública" (Motta; Guazina, 2010). 
Na Tabela 2 um resumo dos enquadramentos, a partir das notícias analisadas acima.

Tabela 2. Funções de enquadramentos nas notícias analisadas

\begin{tabular}{|c|c|}
\hline Funções & Notícias analisadas nos dias 14 e 16/03 e 3/12 \\
\hline $\begin{array}{l}\text { Problemas } \\
\text { identificados }\end{array}$ & $\begin{array}{l}\text { Manifestações foram organizadas por centrais sindicais e movimentos sociais } \\
(14 / 03) \text {; } \\
\text { Rejeição ao impeachment (14/03); } \\
\text { Falta diálogo do governo com a sociedade (14/03); } \\
\text { Insatisfação com Dilma e o PT (16/03); } \\
\text { PT se opõe a Cunha, que revida e aceita pedido de impeachment de Dilma (03/12); }\end{array}$ \\
\hline Causa & $\begin{array}{l}23 \text { cidades participaram dos protestos }(14 / 03) ; \\
\text { Famosos publicam vídeos de apoio a atos pró-impeachment }(14 / 03) ; \\
\text { Protestos não reuniram apenas gente mais rica e grupos de direita }(16 / 03) \text {; } \\
\text { Protestos aconteceram em } 153 \text { cidades }(16 / 03) ; \\
\text { Cunha atende pedido das ruas e aceita pedido de impeachment }(03 / 12) ;\end{array}$ \\
\hline Solução & $\begin{array}{l}\text { "Áecio chama população para marcha anti-Dilma" (14/03); } \\
\text { "Bolsonaro protocola pedido de impeachment na Câmara" (14/03); } \\
\text { Cunha atende pedido das ruas e aceita pedido de impeachment }(03 / 12) ; \\
\text { "Movimentos já planejam outros protestos contra Dilma em abril" }(16 / 03) \\
\text { Multidão foi às ruas de todo o país manifestar contra o governo }(16 / 03) ;\end{array}$ \\
\hline $\begin{array}{l}\text { Avaliação/ } \\
\text { Julgamento }\end{array}$ & $\begin{array}{l}\text { Manifestantes de sindicatos e movimentos sociais alinhados ao PT (14/03); } \\
\text { Manifestantes foram pagos para participar de ato (14/03); } \\
\text { Presidente se diz indignada e parte para o ataque contra Cunha }(03 / 12) \text {; } \\
\text { Cunha foi abandonado pelo PT na Comissão de Ética }(03 / 12) \\
\text { Maior ato desde as Diretas Já (16/03); } \\
\text { Manifestantes fazem vigorosa demonstração de sua insatisfação com Dilma e o PT } \\
\text { (16/03); } \\
\text { "Partido que governa o país desde 2003" (16/03); } \\
\text { "Governo tenta reagir repetindo promessas" (16/03) } \\
\text { "Redutos petistas, como a Bahia e Rio Grande do Norte, também tiveram mani- } \\
\text { festacões com milhares de pessoas" (16/03). }\end{array}$ \\
\hline
\end{tabular}

\section{Considerações finais}

Neste conjunto de notícias é possível observar as tendências alinhadas à política editorial do veículo, favorável ao processo de impeachment - inclusive apresentada em outros estudos sobre jornalismo político. Ressalta-se que não foram raras as ausências nas narrativas que enfatizavam o crime que de fato Dilma havia cometido, as coberturas sobre o impeachment trataram e abordavam, na maioria das vezes, a questão política, a falta de tato político da Presidenta, o que era evidenciado em matérias sem fontes diretas, análises e entrevistas com especialistas, embora não fossem esses recortes o foco deste artigo. É recorrente também, a opção em enfatizar os atos pró-impeachment como mobilizações de pessoas comuns, inconformadas com a corrupção que assola o país, ao contrário as pessoas que participam das manifestações contrárias ao impeachment, são sempre apontadas como militantes de movimentos sociais (principalmente, o MST), sindicatos ou apenas "petistas", isso ocorre principalmente nas matérias analisadas sobre as coberturas dos atos dos dias 13 e 15 de março de 2015.

Observamos nesta análise que é recorrente que escândalos midiáticos sejam o mote da narrativa jornalística, impressos não apenas na Folha de São Paulo, mas em demais veículos impressos, de TV, rádio e 
Golpe no Brasil: o que a mídia tem a ver com isso?

internet. Narrativas que contribuíram, sobremaneira, para o acirramento que desencadeou neste processo político.

Com a função social de informar, o jornalismo também deve ser considerado como uma instituição política (Cook, 2011). Embora os meios de comunicação estejam imbricados em aspectos econômicos e ideológicos, conforme aponta Chauí (2006), e que a propriedade dos meios determina aquilo é que é noticiado, transmitido, falado, como afirma Chomsky (1999), não há que se ignorar as responsabilidades sociais de proprietários e jornalistas na construção daquilo que é real.

Segundo Pérez-Liñan (Chagas, 2016), o novo padrão de instabilidade na América Latina é resultado de quatro fatores: situação econômica desfavorável, escândalos midiáticos, falta de apoio parlamentar e mobilizações nas ruas contra o presidente. Observa-se que no caso brasileiro, os quatro fatores andaram em conjunto, entretanto, o papel da mídia se sobressai. Para a autora chilena Marta Harnecker (2010) a grande maioria das decisões do sistema 'democrático' não são tomadas nos parlamentos, nem pelos presidentes eleitos, mas por entidades que escapam ao controle, como as agências financiadoras internacionais, transnacionais e os meios de comunicação, que são concentrados nas mãos de grandes grupos econômicos.

As atuais batalhas políticas não se ganham com bombas atômicas, mas com bombas midiáticas. A partir da realidade brasileira, essa afirmação se comprova à medida que a mídia, diuturnamente, interfere no jogo político não como coadjuvante, mas como protagonista. Aprofundar sobre essas e outras questões é fundamental para compreender o jogo midiático - acompanhado de seu viés político e econômico - e suas implicações na democracia brasileira, fruto de um projeto de pesquisa que está apenas começando.

\section{Referências}

Alvarez, S. \& Novion, J. (2016). Mídia e a nova metodologia de golpe na América Latina: o caso de Honduras. In J. G. de S. Junior, et al. (org.), Introdução crítica ao direito à comunicação e à informação (pp. 325-335). Brasília: FACUnB.

Biroli, F. \& Miguel, L. (2016). Notícias em disputa. São Paulo: Contexto.

Chaui, M. (2006). Simulacro e poder. São Paulo: Editora Fundação Perseu Abramo.

Chomsky, N. (1999). Segredos, mentiras e democracia. Brasília: Editora Universidade de Brasília.

Costa, A. B.; Sousa Junior, J. G. de; Delduque, M. C.; Oliveira, M. S. de C. \& Dallari, S. G. (org.) (2009). O direito achado da rua: introdução crítica ao direito à saúde. Brasília: CEAD/UnB.

Cook, T. (2011). O jornalismo político. Revista Brasileira de Ciência Política, (6), 203-247.

Fontenelle, A. (2017). Pesquisas eleitorais e colunismo político na cobertura das eleições presidenciais de Brasil (2014) e Argentina (2015). Dissertação de Mestrado. Brasília: UnB. Disponível em: http://repositorio.unb.br/bitstream/10482/23558/1/2017_Andr\%C3\%A9Lu\%C3 \%ADsSoaresFontenelle.pdf

Guazina, L. (2015). Campos em disputa: jornalismo versus política na abordagem do Jornal Nacional sobre o escândalo do mensalão. In Z. Adghirni (org.), Jornalismo e poder legislativo: relações entre mídia e política no Brasil. Curitiba: Editora Appris.

Guazina, L. (2015). Quando cultura política e subcultura profissional andam de mãos dadas: a desconfiança na política em tempos de escândalos. Novos Questionamentos em Mídia e Política. Florianópolis: Insular. (Também disponível em: http://compos.org.br/encontro2014/anais/D ocs/GT05_COMUNICACAO_E_POLITICA/g iicompos_2175.pdf)

Guazina, L.; Prior, H. \& Araújo, B. (s.d.). Enquadramentos de uma crise: o impeachment de Dilma Rousseff em editoriais nacionais e internacionais.

Motta, L. G. \& Guazina, L.(2010). O conflito como metacategoria estruturante da narrativa política. Brazilian Journalism Research, 6(1), 132-149. Disponível em: https://bjr.sbpjor.org.br/ bjr/article/viewFile/251/250 
Lago, C. \& Benetti, M. (orgs) (2010). Metodologia de pesquisa em jornalismo. Petrópolis, RJ: Vozes.

Harnecker, M. (s.d.). América Latina e el socialismo del siglo XXI. Disponível em: www.rebelion. org/docs/101472.pdf. Acesso em: 17 de julho de 2017.

Pereira, F. H.; Moura, D. O. \& Adghirni, Z. L. (orgs.) (2012). Jornalismo e sociedade: teorias e metodologias. Florianópolis: Insular.

Porto, M. (2004). Enquadramentos da mídia e política. In A. A. C. Rubim, (org.), Comunicação e política: conceitos e abordagens. Salvador: Edufba. 